\title{
MIOCARDITE COM CORPÚSCULO DE INCLUSÃO DE PARVOVIRUS EM UM FILHOTE DE CÃO MALTÊS - RELATO DE CASO
}

\author{
Mariana Ribeiro de Castro ${ }^{1}$, Tais Meziara Wilson ${ }^{2}$, Samyla de Almeida Silva ${ }^{1}$, \\ Alessandra Aparecida Medeiros-Ronchi ${ }^{3}$.
}

1- Residente em Patologia Animal, Universidade Federal de Uberlândia UFU, Uberlândia, Minas Gerais, Brasil.

2- Mestrando no Programa de Pós-Graduação em Ciências Veterinárias da Universidade Federal de Uberlândia - UFU, Uberlândia, Minas Gerais, Brasil.e-mail: taismeziara@gmail.com.

3- Professora Doutora em Patologia Animal, Universidade Federal de Uberlândia - UFU, Uberlândia, Minas Gerais, Brasil

\section{Recebido em: 03/10/2016 - Aprovado em: 21/11/2016 - Publicado em: 05/12/2016} DOI: 10.18677/EnciBio 2016B 068

\begin{abstract}
RESUMO
Infecção por parvovírus em cães pode ter como sequela miocardite levando a cardiomiopatia dilatada e insuficiência cardíaca congestiva sem apresentação dos sinais clínicos clássicos de gastroenterite. Relata-se caso de uma cadela de três meses de idade que apresentou morte súbita por miocardite associada ao parvovírus. O animal apresentou prostração e veio a óbito rapidamente, sem outros sinais clínicos associados. Ao exame necroscópico foi evidenciado dilatação cardíaca direita e sinais de insuficiência cardíaca congestiva (congestão hepática, renal e hipóxia cerebral). Ao exame histopatológico evidenciou-se miocardite linfoplasmocitária, degeneração hialina muscular e presença de corpúsculo intranuclear compatível com inclusão por parvovírus em cardiomiócitos. Miocardite por parvovírus em cães filhotes e jovens deve ser considerada como diagnóstico diferencial em casos de morte aguda. O exame necroscópico rigoroso com coleta adequada de amostras e identificação de corpúsculos basofílicos intranucleares nos cardiomiócitos permite o diagnóstico desta síndrome.
\end{abstract}

MYOCARDITIS WITH PARVOVIRUS INCLUSION BODY IN A MALTESE PUPPY CASE REPORT

\begin{abstract}
Parvovirus in dogs can have as myocarditis sequel leading to dilated cardiomyopathy and congestive heart failure without presentation of the classic clinical signs of gastroenteritis. We report the case of a female dog with three months age who had sudden death from myocarditis associated with parvovirus. The animal showed prostration and came to death quickly without other clinical signs associated. At necropsy was evidenced right heart dilation and signs of congestive heart failure (hepatic and renal congestion and cerebral hypoxia). Histopathology revealed a lymphoplasmacytic myocarditis, muscle hyaline degeneration, corpuscle presence of intranuclear inclusion compatible with parvovirus in cardiomyocytes. Myocarditis by
\end{abstract}


parvovirus in puppies and young people should be considered as a differential diagnosis in cases of acute death. The rigorous autopsies with adequate sampling and identification of basophilic intranuclear corpuscles in cardiomyocytes allows diagnosis of this syndrome.

PALAVRAS-CHAVE: Parvovirose, canino, cardiomiopatia dilatada.

\section{INTRODUÇÃO}

A parvovirose canina é uma doença grave, altamente contagiosa, causada por variantes do parvovírus canino. É amplamente reconhecida como a causa mais comum de diarréia viral transmissível em cães e uma das doenças infecciosas mais comuns em cães jovens, levando a altas taxas de mortalidade e morbidade nessa faixa etária em cães (GREENE \& DECARO, 2012; SYKES, 2013). Duas síndromes foram primeiramente descritas por Cooper e colaboradores, tendo como etiologia o vírus da família Parvoviridae. Uma delas é caracterizada por enterite hemorrágica e a outra por miocardite não supurativa e insuficiência cardíaca (COOPER et al., 1979).

O vírus possui uma morfologia esférica e o genoma consiste em cerca de 5000 bases de DNA de cadeia simples. Assim como todos os vírus não envelopados, o parvovírus é extremamente resistente à produtos químicos e inativação ambiental por fatores externos (COTMORE \& TATTERSALL, 2007).

No caso de cães jovens com quadro clínico de vômito e diarréia agudos, a parvovirose deve ser incluída no diagnóstico diferencial. Porém, além da forma entérica, a infecção por parvovírus pode se manifestar com miocardite, levando ao rápido desenvolvimento de insuficiência cardíaca congestiva, arritmia e morte súbita (SIME et al., 2015).

O trato gastroentérico é o sítio primário de dano pelo vírus em aproximadamente $95 \%$ dos casos. Porém, são escassas as lesões em intestino quando há morte súbita e lesões generalizadas de insuficiência cardíaca congestiva em cães com miocardite por parvovírus. O miocárdio apresenta áreas pálidas e flácidas e, microscopicamente, infiltrado inflamatório linfocítico acentuado difuso e miócitos com corpúsculo de inclusão viral intranuclear amplo e basofílico (GELBERG, 2016).

Objetivou-se relatar um caso incomum de miocardite com corpúsculo de inclusão intranuclear, em uma cadela com três meses de idade da raça Maltês, naturalmente infectada com parvovírus canino, alertando para o potencial do vírus da parvovirose em causar miocardite.

\section{RELATO DE CASO}

Uma cadela de três meses de idade, da raça Maltês foi encaminhada ao Setor de Patologia Animal da Universidade Federal de Uberlândia com o histórico de quadro agudo de prostração e episódio de vômito logo antes da morte. O tutor negou antecedentes mórbidos, assim como a possibilidade de trauma, ingestão de corpo estranho e exposição a substâncias tóxicas.

Foi realizado exame necroscópico, com registro fotográfico das lesões macroscópicas e coleta de amostras para avaliação histopatológica. Os achados de necropsia incluíram: coração globoso, com extensas áreas pálidas no miocárdio que aprofundaram ao corte, aumento da câmara do ventrículo direito com parede ventricular discretamente reduzida (dilatação cardíaca) (Figura 1). Observou-se ainda fígado aumentado de volume com bordas abauladas (Figura 2), que ao corte 
fluía líquido sanguinolento. Baço ligeiramente aumentado de volume e rins avermelhados que, ao corte, fluía moderada quantidade de sangue, além de encéfalo com giros discretamente achatados.

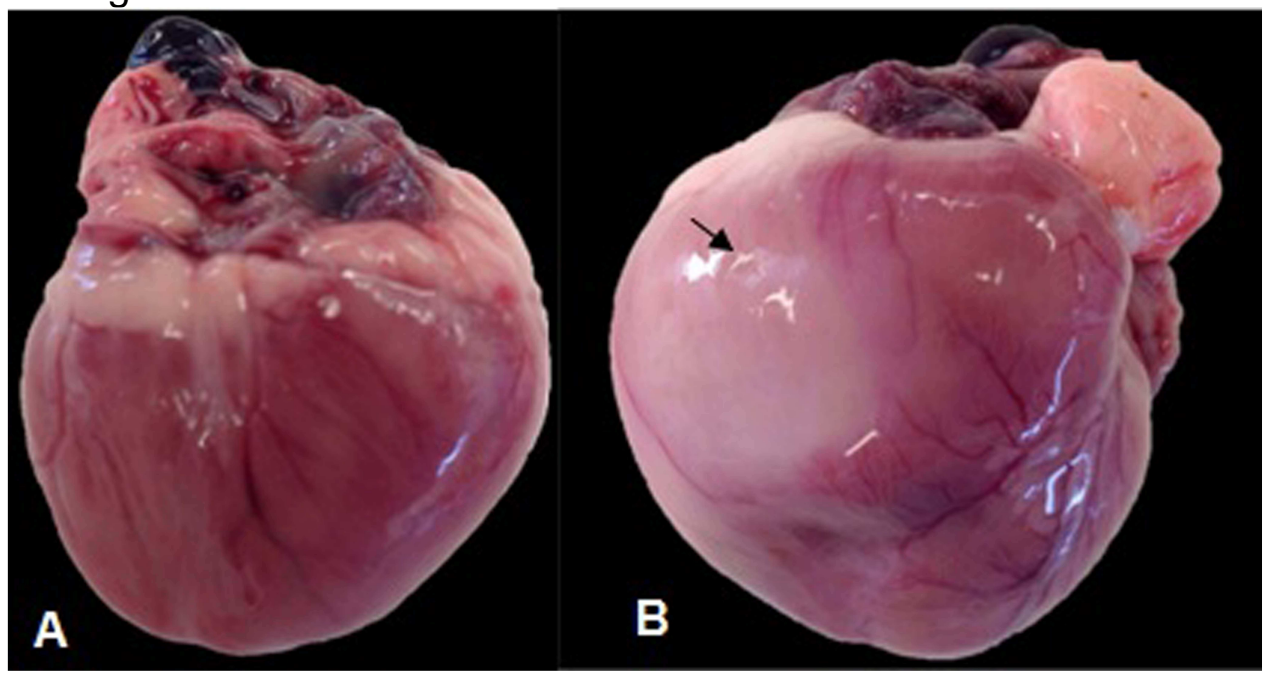

FIGURA 1: Miocardite em cão, fêmea, Maltês, 3 meses. A: Coração globoso. Superfície cardíaca com extensa área pálida (seta).

Fonte: Arquivo pessoal

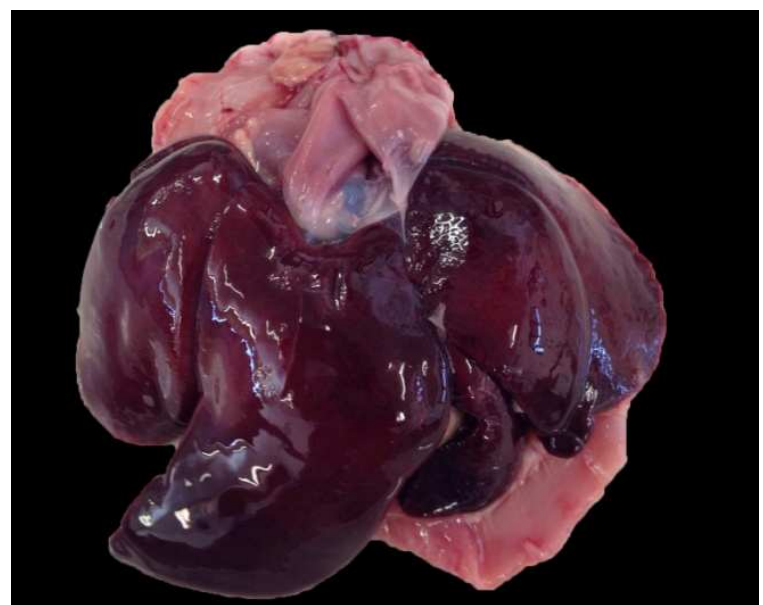

FIGURA 2: Hepatomegalia em cão, fêmea, Maltês, 3 meses. Notar bordas abauladas.

Fonte: Arquivo pessoal

Foram coletados fragmentos de miocárdio, fígado, córtex cerebral, baço e rim, fixados em formol $10 \%$ tamponado e depois incluídos em parafina para confecção de lâminas histológicas coradas por hematoxilina e eosina (H.E). As lâminas foram analisadas ao microscópio de luz para identificação das alterações histopatológicas.

Os principais achados microscópicos foram: fibras cardíacas com perda de estriações e intensamente eosinofílicas (degeneração hialina), moderado infiltrado inflamatório linfoplasmocitário multifocal (miocardite) (Figura $3-$ A) e alguns cardiomiócitos apresentaram corpúsculo de inclusão intranuclear basofílico, compatível com corpúsculo de inclusão por parvovírus (Figura 3 - B). Córtex cerebral com gliose, neurônios encarquilhados intensamente eosinofílicos e núcleos densos 
deslocados para periferia das células (necrose neuronal isquêmica aguda). Fígado com sinusóides repletos de hemácias (hiperemia), hepatócitos aumentados de volume, com pequenos vacúolos citoplasmáticos (edema celular) (Figura 4 - A) e rins com vasos acentuadamente repletos de hemácias (hiperemia) (Figura 4 - B).

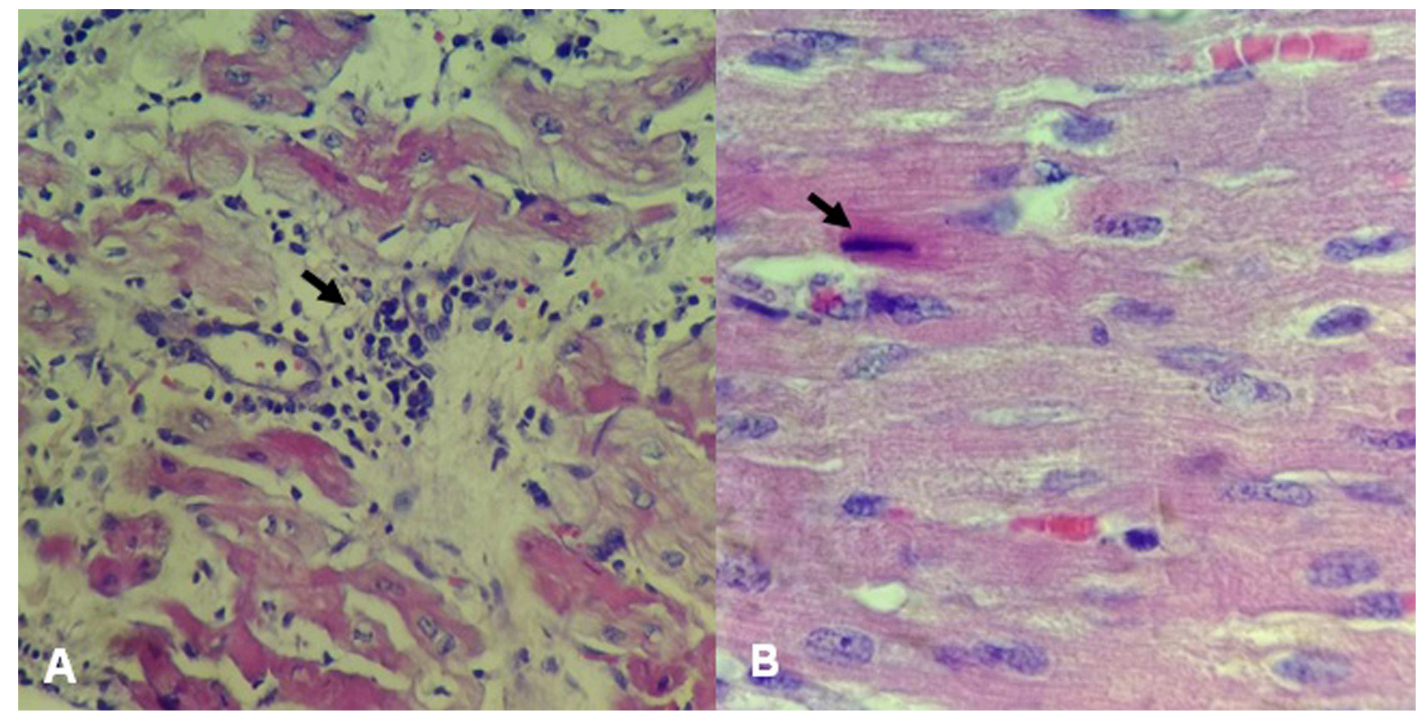

FIGURA 3: Fotomicrografia de miocárdio de cão, fêmea, Maltês, 3 meses. A: Miocardite linfoplasmocitária, degeneração hialina de fibras cardíacas. Notar infiltrado inflamatório linfoplasmocitário (seta). Objetiva 40x, H.E. B: Cardiomiócito com corpúsculo de inclusão de parvovírus intranuclear basofílico (seta). Objetiva 100x, HE.

Fonte: Arquivo pessoal

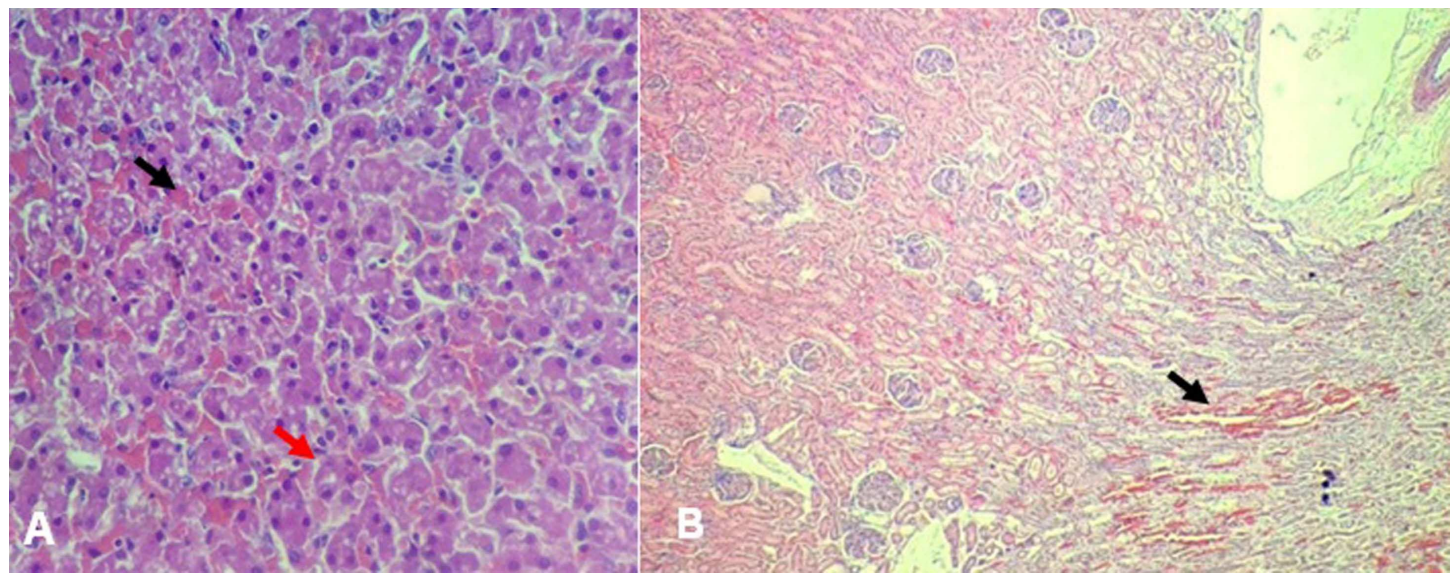

Figura 4: Fotomicrografia de fígado e rim de cão, fêmea, Maltês, 3 meses. A: Sinusóides repletos de hemácias (hiperemia passiva) (seta preta) e edema de hepatócitos (seta vermelha). Objetiva 40x, HE. B: Fotomicrografia de rim apresentando vasos acentuadamente repletos de hemácias (hiperemia passiva) (seta preta). Objetiva 10x, H.E.

Fonte: Arquivo pessoal 
Baseado nos achados macro e microscópicos foi atribuído o diagnóstico de miocardite por parvovírus com corpúsculo de inclusão intranuclear em cardiomiócito.

\section{DISCUSSÃO}

O parvovírus canino tem como tecido alvo para replicação viral as criptas intestinais e órgão linfóides, porém o vírus pode parasitar qualquer tipo de tecido (DECARO \& BUONAVOGLIA, 2012), incluindo o cérebro, fígado, baço e rim (ZHAO et al., 2013). Após penetrar através da cavidade oronasal, o vírus se replica no trato gastroentérico associado a tecidos linfóides e se dissemina por leucócitos infectados até o epitélio das criptas do intestino delgado, causando diarréia (POLLOCK, 1982). Durante o desenvolvimento fetal até as primeiras semanas de vida as células cardíacas se encontram em rápida replicação, ficando susceptíveis a infecção pelo parvovírus. A miocardite por parvovírus é relativamente rara devido à transferência de anticorpos maternais que confere proteção ao filhote por várias semanas (GREENE, 2013; SIME et al., 2015).

A morte súbita na cadela filhote de três meses de idade descrita no presente relato foi resultante de insuficiência cardíaca congestiva direita pela miocardite por parvovírus. Estudos experimentais demonstram ocorrência de miocardite com morte súbita pela infecção com parvovírus e reportam que a cardiomiopatia dilatada com falência cardíaca pode ocorrer em cães com menos de um ano de idade que sobrevivem a miocardite por parvovirose. Porém, existem poucos relatos de ocorrência natural dessa forma da doença, mesmo que experimentalmente se comporte de forma similar à vista na forma natural (LENGHAUS \& STUDDERT, 1984; LIU, 1985; SIME et al., 2015).

A cardiomiopatia dilatada é uma das sequelas de miocardite aguda presente em estudos com modelos animais. A evolução da miocardite em cardiomiopatia dilatada tem três fases envolvidas em sua fisiopatologia. A injúria com ativação da imunidade inata; miocardite aguda com ativação e recrutamento de componentes imunes e desenvolvimento de cardiomiopatia dilatada secundária a fibrose e remodelamento (ELAMM; FAIRWEATHER \& COOPER, 2012).

A alta incidência da parvovirose é devido, em parte, à capacidade do vírus de evoluir para variantes mais virulentas e resistentes (SCHOEMAN; GODDARD \& LEISEWITZ, 2013). O vírus da parvovirose já foi isolado de pulmão, baço, rim, coração, intestino, fígado e miocárdio, demonstrando o caráter sistêmico da doença (PHUKAN et al., 2012).

As lesões encefálicas sugerem hipóxia prolongada com isquemia causada pela miocardite e insuficiência cardíaca. AGUNGPRIYONO e colaboradores (1999) relataram caso de miocardite por parvovírus com lesões encefálicas semelhantes às observadas no presente estudo e também associou as lesões à falha cardíaca ocasionada pela miocardite. Estes autores detectaram o parvovírus no miocárdio pela técnica de imunohistoquímica, sem no entanto, detectá-lo no encéfalo.

A hiperemia renal, assim como as lesões hepáticas, sobretudo a hiperemia observada no relato foram decorrentes da insuficiência cardíaca congestiva direita e são semelhantes aquelas descritas por outros autores (HAYES et al., 1979; AGUNGPRIYONO et al., 1999).

Síndromes distintas são descritas na parvovirose canina. A primeira ocorre em filhotes com menos de duas semanas de idade que apresentam doença generalizada, com necrose induzida por vírus em células que se encontram em rápida divisão. Outra síndrome ocorre em filhotes com 3 a 8 semanas de idade que 
desenvolvem miocardite devido a lesão viral decorrente de infecção prévia não detectada, geralmente sem sinais clínicos. Já cães com até cinco meses de idade podem apresentar morte súbita devido a lesão no miocárdio (GELBERG, 2016).

Cães que sobrevivem à fase aguda da miocardite podem desenvolver alterações cardíacas crônicas como a cardiomiopatia dilatada (SIME et al., 2015). Nesses casos a animal pode vir a óbito sem apresentação clássica dos sintomas gastrointestinais da parvovirose canina e apresentar miocardite com cardiomiopatia dilatada e sinais sistêmicos de insuficiência cardíaca congestiva.

\section{CONCLUSÃO}

Deve-se considerar o diagnóstico de miocardite por parvovirus em cães filhotes e jovens que apresentem morte aguda. O exame necroscópico rigoroso com coleta adequada de amostras e identificação de corpúsculos basofílicos intranucleares nos cardiomiócitos permite o diagnóstico desta síndrome.

\section{REFERÊNCIAS}

AGUNGPRIYONO, D. R.; UCHIDA, K.; TABARU, H.; YAMAGUCHI, R.; TATEYAMA, S. Subacute Massive Necrotizing Myocarditis by Canine Parvovirus Type 2 Infection with Diffuse Leukoencephalomalacia in a Puppy. Veterinary Pathology, v. 36, n. 1, p. 77-80, jan. 1999. Disponível em: < http://vet.sagepub.com/content/36/1/77.long>.

COOPER, B. J.; CARMICHAEL, L. E.; APPEL, M. J.; GREISEN, H. Canine Viral Enteritis. II. Morphologic Lesions in Naturally Occurring Parvovirus Infection. The Cornell Veterinarian, v. 69, n. 3, p. 134-144, abr. 1979. Disponível em: < https://www.ncbi.nlm.nih.gov/pubmed/467076>.

COTMORE, S. F.; TATTERSALL, P. Parvoviral Host Range and Cell Entry Mechanisms. Advances in Virus Research, v. 70, p. 183-232, 2007. Disponível em: $\quad$ http://dx.doi.org/10.1016/S0065-3527(07)70005-2>.doi:10.1016/S0065$3527(07) 70005-2$

DECARO, N.; BUONAVOGLIA, C. Canine Parvovirus--a Review of Epidemiological and Diagnostic Aspects, with Emphasis on Type 2c.Veterinary Microbiology, v. 155, n. 1, p. 1-12, 24 fev. 2012. Disponível em: < http://dx.doi.org/10.1016/j.vetmic.2011.09.007>.doi: 10.1016/j.vetmic.2011.09.007

ELAMM, C.; FAIRWEATHER, D.; COOPER, L. T. Pathogenesis and Diagnosis of Myocarditis.Heart (British Cardiac Society), v. 98, n. 11, p. 835-840, jun. 2012. Disponível em: <https://www.ncbi.nlm.nih.gov/pubmed/22442199>. doi: 10.1136/heartjnl-2012-301686

GELBERG, H.G. Alimentary System and the Peritoneum, Omentum, Mesentery, and Peritoneal Cavity. In: ZACHARY, J. F. Pathologic basis of veterinary disease. 6. ed. St, Louis:Elsevier Health Sciences. p. 324-412. 2016.

GREENE, C. E.; DECARO, N. Canine Viral Enterites. In: GREENE, C. E. Infectious diseases of the dog and cat. 4. ed. St. Louis: Elsevier. p. 67-80. 2012. 
HAYES, M. A.; RUSSEL, R. G.; MUELLER, R. W.; LEWIS, R. J. Myocarditis in Young Dogs Associated with a Parvovirus-like Agent. The Canadian Veterinary Journal, v. 20, n. 5, p. 126, maio 1979. Disponível em:< https://www.ncbi.nlm.nih.gov/pmc/articles/PMC1789543/pdf/canvetj00318-0016.pdf>

LENGHAUS, C.; STUDDERT, M. J. Acute and chronic viral myocarditis. Acute diffuse nonsuppurative myocarditis and residual myocardial scarring following infection with canine parvovirus. The American Journal of Pathology, v. 115, n. 2, p. 316-319, maio $1984 . \quad$ Disponívl em:< https://www.ncbi.nlm.nih.gov/pmc/articles/PMC1900497/pdf/amjpathol001820182.pdf>.

LIU, S.-K. Myocarditis and Cardiomyopathy in the Dog and Cat. Heart and Vessels, v. 1, n. 1, p. 122-126, 1985.

PHUKAN, A., CHAKRABORTY, A., DEKA, D.,BORO, P. K. Pathology of parvovirus infection in dogs. Indian Journal of Veterinary Pathology, v. 36, n. 2, p. 148-151, 2012.

$<$ http://www.indianjournals.com/ijor.aspx?target=ijor:ijvp\&volume=36\&issue=2\&article $=004>$

SCHOEMAN, J. P.; GODDARD, A.; LEISEWITZ, A. L. Biomarkers in canine parvovirus enteritis. New Zealand Veterinary Journal, v. 61, n. 4, p. 217-222, 1 jul. 2013. Disponível em: <https://www.ncbi.nlm.nih.gov/pubmed/23477413>. doi: $10.1080 / 00480169.2013 .776451$

SIME, T. A.; POWELL, L. L.; SCHILDT, J. C.; OLSON, E. J. Parvoviral Myocarditis in a 5-Week-Old Dachshund. Journal of Veterinary Emergency and Critical Care, v. 25 , n. $6, \quad$ p. 765-769, 1 nov. 2015. Disponível em: <http://dx.doi.org/10.1111/vec.12347>.doi:10.1111/vec.12347

SYKES, J. E. Canine Parvovirus Infections and Other Viral Enteritides. In: Canine and Feline Infectious Diseases. St. Louis: Elsevier Health Sciences. p.141-152. 2013.

ZHAO, Y.; LIN, Y.; ZENG, X.; LU, C.; HOU, J. Genotyping and pathobiologic characterization of canine parvovirus circulating in Nanjing, China. Virology Journal, v. $10, \quad$ p. 272, 2013. Disponível em: < http://virologyj.biomedcentral.com/articles/10.1186/1743-422X-10272>.doi: $10.1186 / 1743-422 X-10-272$ 